\title{
RESENHA
}

\section{A HISTÓRIA DA IMPRENSA PERIÓDICA PARA A INFÂNCIA E A JUVENTUDE ITALIANA}

DOI: http://dx.doi.org/10.1590/2236-3459/64947

\section{THE HISTORY OFTHE PERIODICAL PRESS FOR ITALIAN CHILDREN AND YOUTHS}

\author{
Maria Helena Camara Bastos \\ Pontifícia Universidade Católica do Rio Grande do Sul, Brasil.
}

\section{$\cos 80$}

MEDA, Juri (dir.). Collana storia della stampa periodica per l'infanzia e la gioventù. Firenze: Nerbini, 2011.

Juri Meda é professor de História da Escola e das Instituições Educativas no Dipartimento di Scienze della formazione, dei beni culturali e del turismo da Università degli studi di Macerata/Itália. É pesquisador e integrante do conselho diretivo do Centro di documentazione e ricerca sulla storia del libro scolastico e della letteratura per l'infanzia/Cesco. Integra a comissão editorial da revista Internacional History of Education \& Children's Literature. Desde 2009 dirigi a coleção Nerbiniana Storia della Stampa Periodica per l'Infanzia e la Gioventù da Editora Nerbini de Florença/Itália. Tem publicado numerosos artigos e ensaios, a maior parte dedicada ao processo de nacionalização da infância na idade contemporânea. Em 2013, junto com Ana Maria Badanelli organizou a coletânea La historia dela cultura escolar em Italia y em Espana: balance y perspectivas.

$\mathrm{Na}$ apresentação da coleção Juri Meda chamou a atenção da indiferença da comunidade científica italiana com pesquisas que tomam como objeto e sujeito a imprensa periódica voltada para a infância e a juventude. Salientou que esse corpus documental permite ser analisado de diferentes perspectivas: desde a história da 
imprensa à história das editoras; da história da ilustração à história do processo cultural e da mídia; da história da educação à história da literatura para a infância e da leitura (2011a, p. 8).

A imprensa periódica para a infância e juventude compreende uma variedade de publicações - revistas recreativas, revistas em quadrinhos, suplementos voltados às crianças em periódicos diários, imprensa escolar, boletins de associações de jovens ou grêmios estudantis, ilustradas ou não -, mas todas com finalidade educativa, recreativa, socializante ou de propaganda para públicos de diferentes idades e gênero.

A primeira obra publicada na coleção é de Fabiana Loparco (2011a) - I bambini e la Guerra: II Corriere dei Piccoli e il primo conflito Mondiale (1915-1918), que analisa o suplemento dominical ilustrado do jornal Corriere della Sera (1876), criado em 1906 e editado até 1995. Centra sua análise em como o periódico foi um importante instrumento de propaganda ideológica durante a Primeira guerra (1914-1918), mobilizando a criança com valores patrióticos e, ao mesmo tempo, estimulando e cultivando a fantasia, a curiosidade, a inteligência dos pequenos leitores com histórias edificantes de altruísmo, respeito aos pais e adultos, curiosidade sobre o novo e diferente. Para a autora, o periódico foi "um exemplo extraordinário de assistência moral" à infância durante o conflito (2011a, p. 193).

O segundo volume da coleção é de llaria Mattioni, intitulado Da grande farò la Santa: modelli etici e valori religiosi nella stampa cattolica femminile per l'infanzia e la gioventù (1950-1979), em que analisa diferentes periódicos católicos destinados à crianças, adolescentes e moças, das décadas de 1950 a 1980, e voltados para a formação da nova geração do pós-guerra e em um contexto de grandes mudanças. Destaca a função moralizadora dos impressos, com leituras edificantes e benéficas para o público leitor, especialmente para a juventude católica feminina, veiculando uma moral católica e propondo um modelo tradicional para as mulheres e futuras mães de família. Nesta perspectiva a autora conclui que, pelos periódicos católicos analisados, "educar para a vida a leitora significava também ajudá-la a ser protagonista ativa da vida social, em seupresente de meninas e adolescentes, bem como em seu papel de futura mulher adulta" (2011b, p. 232).

Mattioni também é autora do quarto volume da coleção - Inchiostro e incenso: il Giornalino: storia e valori educativi di um periodico cattolico per ragazzi (1924-1979), em que analisa a iniciativa da Pia Società San Paolo de Roma de publicar semanalmente um periódico ilustrado para meninos e rapazes, considerado o mais longevo da Itália e da Europa. O estudo resulta de pesquisa documental e história oral, em que a autora reconstitui a história desse periódico católico com finalidades e valores educativos: instruir, divertir, educar, que não permanecerem estáticos em mais de 50 anos, diante de outras publicações para o mesmo público leitor. Para analisá-lo faz uma retrospectiva da imprensa infanto-juvenil na Itália, aborda a história da criação da Sociedade São Paulo e da casa editora, e a história do periódico no período do fascismo, no pós-guerra, anos 1960 e 1970. Dedica especial atenção às relações do periódico com seu leitor pela análise da seção Conversazione con i miei ragazzi, nos anos 1930, e, posteriormente, com a publicação das cartas dos jovens leitores. 
Silvia Assirelli é a autora do terceiro volume da coleção, intitulado Paradigma Bemporad: percorsi e linee evolutive dell'illustrazione nel libro per l'infanzia in Italia tra ottocento e novecento, no qual analisa o processo de ilustração nos livros de literatura para a infância e a juventude nas duas décadas finais do século 19 até 1938, focando especialmente a editora Bemporad (1889-1938). A pesquisa reúne vários aportes disciplinares para abordar seu objeto de pesquisa: história da literatura, história da ilustração, história do livro e da leitura e a história editorial da Itália. Com esse suporte teórico e ampla base documental - o livro, os catálogos das editoras, prospectos promocionais, publicidade, contratos, escritura comercial, correspondências, imprensa e outros -, a autora foca a mediação que se estabelece, na produção do livro não-escolar, entre questões educativas, pressupostos ideológicos e exigências editoriais, especialmente comerciais, que incidem sobre a evolução da ilustração do livro de literatura infantil e juvenil, em um período de mais de 50 anos.

Falce e Fumetto: storia della stampa periódica socialista e comunista per l'infanzia in Italia (1893-1965), é o quinto livro coleção e é uma coletânea, organizada por Juri Meda junto com sete pesquisadores, que apresentam diferentes estudos sobre a imprensa periódica socialista e comunista para a infância na Itália e na Europa. Organiza-se em nove capítulos.

Para Meda (2013) esse corpus documental é muito particular, inédito e tem tido pouca atenção dos historiadores da educação europeus, especialmente do período que antecede a segunda grande guerra. O organizador assinala que a presente publicação visa a valorizar esta experiência editorial diversificada e também ideologicamente homogênea, em uma perspectiva de longa duração, que busca mostrar as continuidades e descontinuidades no âmbito interno dos periódicos analisados. O conjunto dos capítulos busca problematizar algumas questões: o modelo de infância que inspira os impressos; quem eram seus leitores: perfil real ou ideal; a composição social e ideológica do público infantil: infância proletária, da pequena e média burguesia urbana; o destinatário: meninos/rapazes ou meninas/moças; o contexto histórico dos partidos que tiveram a iniciativa editorial; os objetivos da publicação: periódico educativo e moralizante ou periódico de propaganda e politização; em uma abordagem interdisciplinar, com categorias interpretativas heterogêneas, mas que permitem um arcabouço de pesquisa inovador e complexo. Em síntese, os estudos com a imprensa periódica socialista e comunista para a infância se inserem no debate internacional sobre o processo de politização da infância no curso do século 20.

Cabe assinalar que a coleção Storia della stampa periodica per l'infanzia e la gioventù é um caleidoscópio de distintas abordagens teóricas e metodológicas, com amplo e diversificado corpus documental, focando em distintas publicações periódicas voltadas à infância e à juventude, editadas por diferentes setores da sociedade: jornalístico, católico, socialista, comunista. Por tudo isso, acreditamos que é um estímulo para as pesquisas com imprensa periódica, especialmente de educação e ensino, para diferentes públicos leitores e de distintos setores sociais e ideológicos no Brasil. 


\section{Referências}

MEDA, Juri (dir.). Per una storia della stampa periodica per l'infanzia e la gioventù in Italia tra '800 e '900. In. LOPARCO, Fabiana. I bambini e la guerra: il Corriere dei Piccoli e il primo conflito Mondiale (1915-1918). Firenze: Nerbini, 2011, p.7-24.

MEDA, Juri (dir.). Falce e fumetto: storia della stampa periodica socialista e comunista per I'infanzia in Italia tra (1893-1965). Firenze: Nerbini, 2013.

LOPARCO, Fabiana. I bambini e la guerra: II Corriere dei Piccoli e il primo conflito Mondiale (1915-1918). Firenze: Nerbini, 2011.

MATTIONI, Ilaria. Da grande farò la Santa: modelli etici e valori religiosi nella stampa cattolica femminile per l'infanzia e la gioventù (1950-1979). Firenze: Nerbini, 2011.

MATTIONI, Ilaria. Inchiostro e incenso: il Giornalino: storia e valori educativi di um periodico cattolico per ragazzi (1924-1979). Firenze: Nerbini, 2012.

ASSIRELLI, Silvia. Paradigma Bemporad: percorsi e linee evolutive dell'illustrazione nel libro per l'infanzia in Italia tra ottocento e novecento. Firenze: Nerbini, 2012.

MARIA HELENA CAMARA BASTOS é professora na Pontifícia Universidade Católica do Rio Grande do Sul. Professora visitante na Università degli studi di Macerata/Itália.

Endereço: Rua Eng. Álvaro Nunes Pereira, 340/906 - 90570-110 - Porto Alegre - RS

- Brasil.

E-mail: mhbastos1950@gmail.com.

Recebido em 23 de maio de 2016.

Aceito em 12 de setembro de 2016. 